\title{
Increased Responsiveness to Novelty is Associated with Successful Cognitive Aging
}

\section{Citation}

Daffner, Kirk R., Katherine K. Ryan, Danielle M. Williams, Andrew E. Budson, Dorene M. Rentz, David A. Wolk, and Phillip J. Holcomb. 2006. "Increased Responsiveness to Novelty Is Associated with Successful Cognitive Aging." Journal of Cognitive Neuroscience 18, no. 10: 1759-1773.

\section{Published Version}

10.1162/jocn.2006.18.10.1759

\section{Permanent link}

http://nrs.harvard.edu/urn-3:HUL.InstRepos:12605385

\section{Terms of Use}

This article was downloaded from Harvard University's DASH repository, and is made available under the terms and conditions applicable to Other Posted Material, as set forth at http:// nrs.harvard.edu/urn-3:HUL.InstRepos:dash.current.terms-of-use\#LAA

\section{Share Your Story}

The Harvard community has made this article openly available.

Please share how this access benefits you. Submit a story.

Accessibility 


\title{
Increased Responsiveness to Novelty is Associated with Successful Cognitive Aging
}

\author{
Kirk R. Daffner ${ }^{1}$, Katherine K. Ryan ${ }^{1}$, Danielle M. Williams ${ }^{1}$, \\ Andrew E. Budson ${ }^{1,2}$, Dorene M. Rentz ${ }^{1}$, David A. Wolk ${ }^{3}$, \\ and Phillip J. Holcomb ${ }^{2}$
}

\begin{abstract}
The animal literature suggests that exposure to more complex, novel environments promotes neurogenesis and cognitive performance in older animals. Studies in humans indicate that participation in intellectually stimulating activities may serve as a buffer against mental decline and help to sustain cognitive abilities. Here, we show that across old adults, increased responsiveness to novel events (as measured by viewing duration and the size of the $\mathrm{P} 3$ event-related potential) is strongly linked to
\end{abstract}

\section{INTRODUCTION}

The propensity to orient to novelty may contribute not only to the development of intellectual capacities in children (Hunt, 1965; Piaget, 1952) but also to sustaining cognitive performance throughout the lifespan. Research suggests that in older animals, interaction with a more complex environment influences neurogenesis, synaptogenesis, and dentritic complexity (Kempermann, Kuhn, \& Gage, 1997; Connor, Melone, Yuen, \& Diamond, 1981), and those animals more engaged by novel stimuli (as measured by their spontaneous behavioral responses to stimuli) tend to exhibit greater preservation of cognitive functioning (Rowe, Spreekmeester, Meaney, Quirion, \& Rochford, 1998). Moreover, as humans age, continued interest in the novel aspects of their environment and exposure to intellectually stimulating activities may sustain cognitive functioning, create a buffer against mental decline, and even promote longevity (Scarmeas et al., 2003; Wilson et al., 2002; Swan \& Carmelli, 1996). Although the biological sources of these findings remain to be determined, these studies have influenced clinicians to encourage their older patients to remain cognitively active.

Event-related potentials (ERPs) have been an important source of data regarding age-related differences in

${ }^{1}$ Brigham and Women's Hospital, Harvard Medical School, ${ }^{2}$ Edith Nourse Rogers Memorial Veterans Hospital, ${ }^{3}$ Tufts University better performance on neuropsychological tests, especially those involving attention/executive functions. Cognitively high performing old adults generate a larger P3 response to visual stimuli than cognitively average performing adults. These results suggest that cognitively high performing adults successfully manage the task by appropriating more resources and that the increased size of their P3 component represents a beneficial compensatory mechanism rather than less efficient processing.

the processing of novel and target stimuli. The ERP literature suggests several common age-related changes are associated with the novelty oddball paradigm, including the amplitude, scalp distribution, and latency of the P3 component. Most studies have found an overall age-related decline in the P3 amplitude to novel and target stimuli (e.g., Walhovd \& Fjell, 2001; Anderer, Semlitsch, \& Saletu, 1996; Fabiani \& Friedman, 1995; Verleger, Neukäter, Kömpf, \& Vieregge, 1991). Alterations in $\mathrm{P} 3$ amplitude have been interpreted as reflecting changes in the way in which attention or other processing resources are allocated to stimuli (Polich, 1996; Wickens, Kramer, Vanasse, \& Donchin, 1983). A frequent observation in the literature is that in older individuals, the novelty $\mathrm{P} 3$ component, like the target $\mathrm{P} 3$ component, exhibits a more anteriorly oriented scalp distribution (e.g., Anderer et al., 1996; Fabiani \& Friedman, 1995; Friedman, Simpson, \& Hamberger, 1993). Changes in the scalp distribution of the $\mathrm{P} 3$ component have been attributed to age-related frontal lobe dysfunction that may alter anterior neural components that mediate the P3 response to novel and target events (Friedman, Kazmerski, \& Cycowicz, 1998; Friedman et al., 1993). Finally, many studies have shown that the P3 latency in response to target and novel events increases with age (e.g., Fjell \& Walhovd, 2004; Anderer et al., 1996; Polich, 1996; Fabiani \& Friedman, 1995; Beck, Swanson, \& Dustman, 1980). These findings are commonly linked to age-associated slowing in the process of evaluating stimuli or updating working memory (Polich, 1996; 
Kutas, McCarthy, \& Donchin, 1977). Because the target P3 latency has been investigated most extensively, it will be one of the issues addressed in this article.

Although some studies in the ERP literature have matched different age groups for IQ and have carefully excluded older subjects with possible dementia (e.g., Fjell \& Walhovd, 2004; Fabiani \& Friedman, 1995; Friedman et al., 1993), many studies have provided only a brief description of the participants and only a limited assessment of cognitive, psychological, and functional status. It is plausible that there have been substantial differences in the mixture of cognitively high, average, and low performing subjects among the various age groups studied, which may have contributed to the observed agerelated differences in $\mathrm{P} 3$ response. To address this issue, in our research, we have tried to carefully delineate the neuropsychological status of different subject groups.

The current investigation utilized a variant of the novelty oddball paradigm that has been used in the study of young adults (Daffner, Mesulam, Calvo, et al., 2000; Daffner, Mesulam, Scinto, Calvo, et al., 2000; Daffner et al., 1998), patients with focal brain lesions (Daffner et al., 2003; Daffner, Mesulam, Scinto, Acar, et al., 2000), patients with mild Alzheimer's disease (AD; Daffner et al., 2001), and, most recently, cognitively high performing individuals across the adult lifespan (Daffner et al., 2006). In contrast to the traditional oddball paradigm in which stimulus durations are predetermined, in this version, subjects control how long they look at each stimulus by pressing a button that leads to the onset of the next stimulus. In keeping with a tradition in experimental psychology, viewing duration is used as an index of visual attention and exploratory behavior (Daffner, Scinto, Weintraub, Guinessey, \& Mesulam, 1994; Berlyne, 1960).

Although in the traditional novelty oddball paradigm, novel events serve as distracters from the primary task of identifying targets, in the subject-controlled variant of the paradigm used here, novel stimuli serve as "opportunities" to explore potentially interesting or significant aspects of the environment. Because the novel stimuli in this paradigm are both novel and very relevant to the task, the ERP response in the $\mathrm{P} 3$ temporal interval likely reflects a mixture of both $\mathrm{P} 3 \mathrm{a}$ and $\mathrm{P} 3 \mathrm{~b}$ components. For the purposes of this study, the $\mathrm{P} 3$ response to different stimulus types will be characterized in terms of amplitude and scalp distribution within a designated temporal window, without using additional analyses (PCA or ICA) for further decomposition of the waveforms. ${ }^{1}$

Prior ERP investigations that used this variant of the novelty oddball paradigm have demonstrated that in healthy young adults, P3 amplitude and viewing duration were much larger in response to novel stimuli than in response to repetitive standard stimuli (Daffner, Mesulam, Scinto, Calvo, et al., 2000; Daffner et al., 1998). Across subjects, the amplitude of the novelty P3 response strongly predicted the duration of viewing directed toward novel relative to standard stimuli. ${ }^{2}$ Within subjects, the novel stimuli that elicited the largest P3 responses were associated with the longest viewing durations. Results from our studies of patients with focal brain lesions suggested that prefrontal and posterior parietal regions comprise two nodes of a network for responding to and processing novelty. Injury to this network is indexed by reduced novelty $\mathrm{P} 3$ amplitude, which is tightly associated with diminished attention to novel stimuli. The prefrontal cortex appears to play a major role in decisions about the allocation of attentional resources, whereas the posterior parietal cortex appears to have the neural machinery for updating internal models about the environment. Patients with $\mathrm{AD}$, even of mild severity, also have been shown to have a markedly reduced novelty P3 component and to distribute their viewing time evenly between novel and repetitive standard stimuli (Daffner et al., 2001). Across AD subjects, the novelty $\mathrm{P} 3$ amplitude accounted for more than half of the variance in viewing duration of novels relative to standards. In both $\mathrm{AD}$ and frontal patients, the amplitude of the novelty $\mathrm{P} 3$ as well as the viewing duration of novel stimuli inversely correlated with the degree of a patient's apathy as measured by caregiver reports. Overall, the results of these studies suggest that the subject-controlled variant of the novelty oddball paradigm is an informative tool for evaluating differences in attention to novelty and exploratory activity in humans and linking these behaviors to underlying brain electrophysiology. It is well suited for investigating the relationship between responses to novelty and different patterns of normal aging.

Recently, we reported on the behavioral and ERP results using this variant of the novelty oddball paradigm with old, middle-aged, and young individuals who were matched for cognitive functioning, as defined by their performance in the top third ( $\geq 67$ th percentile) on neuropsychological tests according to age-appropriate published norms (Daffner et al., 2006). Compared with cognitively high performing young and middle-aged subjects, cognitively high performing old subjects did not exhibit a decline in their behavioral engagement by novel events (as defined by viewing durations). Cognitively high performing old subjects also did not demonstrate an increase in P3 latency or changes in target detection accuracy or reaction time (RT). The most remarkable finding was that cognitively high performing old subjects had a larger P3 component to novel and standard stimuli than their younger counterparts. In addition, their P3 component was more anteriorly distributed than was observed in younger subjects. As summarized below, we suggested that the age-related difference may have represented a successful compensatory mechanism used by these cognitively high functioning elders.

We recognize that post hoc interpretations of the functional significance of an age-related increase in the size of an ERP component or shift in its scalp distribution is problematic (Friedman, 2003). Reports of age- 
related changes in resource allocation (as measured by differences in regional cerebral blood flow (rCBF) activity in functional imaging studies or amplitude of components in ERP studies) or neural networks recruited (as indicated by differentially activated regions or differences in ERP scalp distribution) vary across studies. For example, functional imaging studies frequently have reported age-related increases in frontal lobe activity (and unlike young subjects, the recruitment of both hemispheres) in tasks involving working memory (ReuterLorenz et al., 2000; Rypma \& D'Esposito, 2000), episodic memory (Logan, Sanders, Snyder, Morris, \& Buckner, 2002; Rosen et al., 2002; Madden et al., 1999), source memory (Cabeza, Anderson, Locantore, \& McIntosh, 2002), but not semantic memory (Madden et al., 2002). In some cases, these age-associated increases in neural activity and more widely distributed responses have been interpreted as reflecting compensatory activity (perhaps in response to other age-associated declines in physiologic activity), whereas in other cases, they have been viewed as reflecting diminished processing efficiency (i.e., reduced selective recruitment of specialized neural mechanisms) (Friedman, 2003; Cabeza et al., 2002; Logan et al., 2002; Nielson, Langenecker, \& Garavan, 2002).

Several investigators have discussed strategies to help determine whether age-related changes in the size or distribution of neural activity represent a compensatory mechanism or reduced efficiency in response to a designated cognitive or behavioral task (Friedman, 2003; Cabeza et al., 2002; Logan et al., 2002). One method that has been advocated (Friedman, 2003; Cabeza et al., 2002) is to divide older subjects into groups according to their performance on neuropsychological tests or demographic variables. A priori predictions are generated about the how the groups will diverge in their performance on the experimental task and how their pattern of metabolic, rCBF, or electrophysiological responses will differ. This approach assumes that if there are differences in indices of neural activity between low and high performing old subjects and the latter group performs comparably to their younger counterparts, the pattern associated with high performing old subjects (e.g., wider activation of cortex) likely represents a successful compensatory mechanism (Cabeza et al., 2002; Rosen et al., 2002; Reuter-Lorenz et al., 2000). ${ }^{3}$ Because our findings of an age-related increase in the P3 amplitude to visual stimuli had not been reported in the literature and because much of the previous research had not carefully controlled for the potential impact of cognitive performance on age-associated effects, we suspected that our results were a reflection of the high cognitive competence of our old subjects. We hypothesized that the age-related increase in size of the $\mathrm{P} 3$ response was not because of less efficient processing but reflected a compensatory process utilized by these cognitively successful elders, who likely had consider- able cognitive reserve (Stern, 2002; Katzman, 1993; Satz, 1993). The significance of the anterior shift in the scalp distribution of the P3 was less clear, because this is a common age-related finding in the literature. One possibility is that the shift also represents a compensatory process involving increased effortful frontal activity.

Interpretation of our results was limited by the absence of a cognitively average performing control group of old subjects against which to make comparisons. As discussed earlier, one method for testing our hypotheses would be to demonstrate significant differences between cognitively high and cognitively average performing old adults in their behavioral and $\mathrm{P} 3$ responses on our novelty oddball paradigm. We did not choose a "low functioning" group against which to make comparisons because of our concern that they might not be representative of "normal aging," as many members of such a group may be in the early stages of a dementing illness, especially because our plan was to require all subjects to have a baseline intellectual capacity in the average to superior range.

The current study sought to examine if there were differences in the way in which cognitively high and cognitively average old individuals process novel and target events. We were particularly interested in whether old individuals who exhibit successful cognitive aging are more engaged by novelty and whether the age-related increase in P3 amplitude among cognitively high performers reported in our previous study (Daffner et al., 2006) reflects compensatory activity or less efficient processing. To address these issues, we generated four a priori hypotheses, in keeping with the strategy advocated by Friedman (2003) and Cabeza et al. (2002). (1) Cognitively high performing old individuals would be more engaged by novel stimuli (as indexed by relatively longer subjectcontrolled viewing durations of novel stimuli) than cognitively average performing old individuals. (2) Cognitively high performing old individuals would have shorter P3 latencies in response to designated targets than cognitively average performing old individuals. (3) Cognitively high performing old subjects would have a larger P3 response to novel stimuli than cognitively average performing old subjects. (4) Cognitively high performing older individuals would have a more anteriorly distributed P3 response to novel stimuli than cognitively average performing older individuals.

\section{METHODS}

\section{Participants}

Participants were recruited through community announcements. After completing informed consent, participants underwent an evaluation that included a medical, neurological, and psychiatric history; a formal neurological examination; neuropsychological testing; and completion of questionnaires surveying mood and socioeconomic 
status. Participants had to be 65-85 years old, Englishspeaking, have $\geq 12$ years of education, a Mini-Mental State Exam (MMSE) score (Folstein, Folstein, \& McHugh, 1975) of $\geq 26$, and an estimated IQ on the American Modification of the National Adult Reading Test (AMNART; Ryan \& Paolo, 1992) of $\geq 100$. Subjects were excluded if they had a history of central nervous system diseases or major psychiatric disorders based on Diagnostic and Statistical Manual of Mental Disorders, Fourth Edition criteria (American Psychiatric Association, 1994), a history of clinically significant medical diseases, corrected visual acuity worse than 20/40, a history of clinically significant audiological disease, a Geriatric Depression Scale score (Yesavage, Rose, \& Lapp, 1981) of $\geq 10$, or focal abnormalities on neurological examination consistent with a lesion in the central nervous system.

Cognitive status was operationally defined based on performance on the following six neuropsychological tests: (1) Digit Span subtest of the Wechsler Adult Intelligence Scale III (Wechsler, 1997a); (2) Controlled Oral Word Association Test (COWAT; Ivnik, Malec, Smith, Tangalos, \& Petersen, 1996); (3) Logical Memory II subtest of the Wechsler Memory Scale III (WMS-III; Wechsler, 1997b); (4) Visual Retention Test (Youngjohn, Larrabee, \& Crook, 1993); (5) Boston Naming Test (BNT; Tombaugh \& Hubley, 1997); (6) category (animal) fluency (Spreen \& Strauss, 1998). Each of the tests has available norms through late adulthood. Also, the tests evaluate performance in several major cognitive realms, including attention/executive functions (Digit Span, COWAT), verbal memory (WMS-III), visual memory (Visual Retention Test), language (BNT), and semantic access (category fluency). To meet the criteria for a cognitively high performer, subjects had to score in the top third ( $\geq 67$ th percentile) of published age-matched norms on four or more of the six cognitive tests. To meet criteria for a cognitively average performer, subjects had to score in the middle third (33rd to 66th percentile) of published age-matched norms on three or more of the six cognitive tests. A composite score was computed for each subject by averaging performance (percentile score) on each of the neuropsychological tests. Because performance on our experimental task was particularly dependent upon attention/executive functions, the average percentile score on Digit Span and COWAT was also computed. Subjects also completed the AMNART and the Raven's Progressive Matrices Test (Raven, Court, \& Raven, 1995) to determine an estimated IQ score and the MMSE to obtain a gross measure of current mental state.

\section{Experimental Procedures}

The experimental procedures used were analogous to the ones described in prior reports (e.g., Daffner et al., 2001, 2003). Two hundred fifty line drawings, white on black background, were presented in five blocks of 50 , each at the center of a high-resolution computer monitor. All stimuli subtended a visual angle of approximately $2.75^{\circ}$ along their longest dimension. There were three categories of visual stimuli: (1) a repetitive standard stimulus (a triangle), 70\% frequency; (2) a target stimulus (upside down triangle), approximately 15\% frequency; and (3) novel stimuli, randomly drawn from a set of unusual/unfamiliar line drawings (e.g., impossible or fragmented objects) shown only one time each, approximately $15 \%$ frequency, many of which came from the collection of drawings that have been used by Kroll and Potter (1984) and Kosslyn et al. (1994) (Figure 1). Stimuli appeared within a fixation box subtending a visual angle of approximately $3.5^{\circ} \times 3.5^{\circ}$ that remained on the screen at all times.

Participants were informed that the experiment involved the study of brain wave activity as they looked at different kinds of drawings. We emphasized that they could view each picture for however long or short they liked. They controlled the viewing duration by a button press that led to the erasure of the current stimulus and the onset of a blank screen, followed by the presentation of the next stimulus. Also, participants were told to respond to the designated target stimulus by pressing a foot pedal (ipsilateral to the button press). Instructions indicated that accuracy was more important than speed.

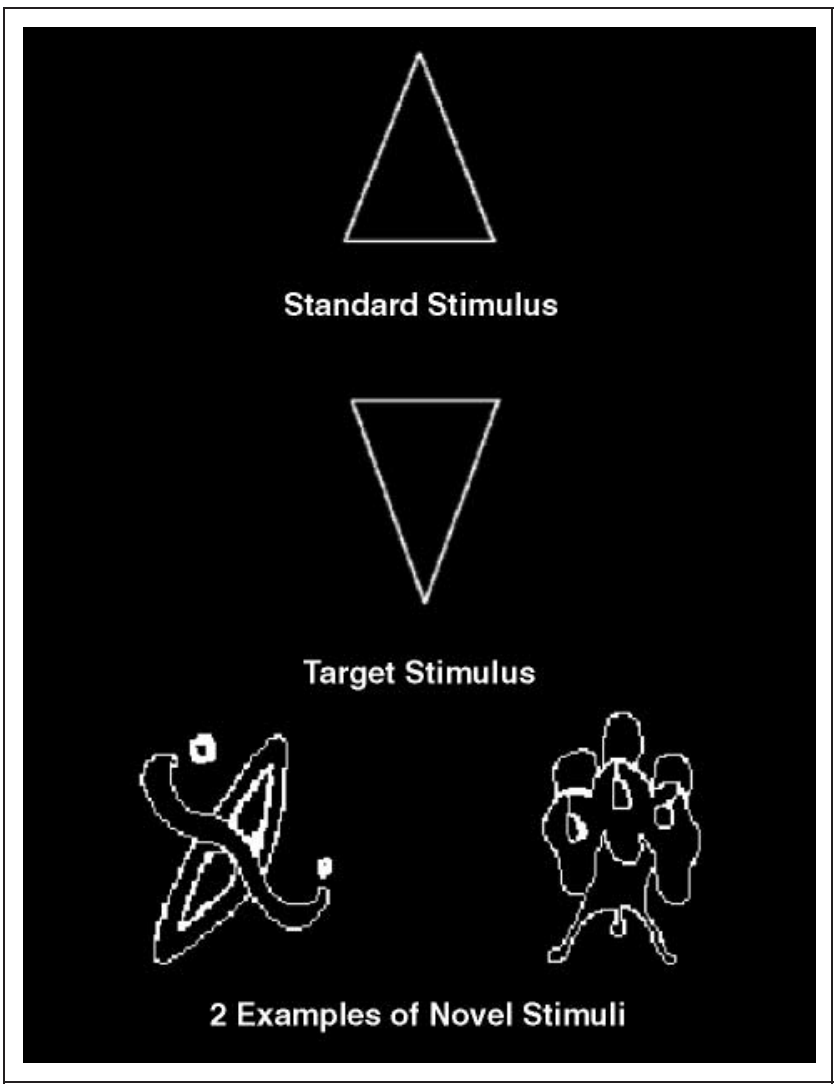

Figure 1. Repetitive standard stimulus (70\% frequency), target stimulus (15\% frequency), and two examples of novel stimuli (15\% frequency). 
Left and right button press/foot pedal were counterbalanced for both subject groups. Although viewing durations were calculated by subtracting the stimulus onset time from the button press time, all stimuli were displayed for a minimum duration of $600 \mathrm{msec}$. Subjects also participated in two other conditions not reported here. The order of the conditions was counterbalanced.

\section{Event-related Potential Recordings}

An electrode cap (Electro-Cap International, Eaton, $\mathrm{OH}$ ) was used to hold the 35 active tin electrodes to the scalp whose locations were based on the international 10-20 system. Electrodes were arranged in five columns, each with seven anteroposterior sites (see Figure 2). The midline (ML) sites were $\mathrm{FPz}, \mathrm{Fz}, \mathrm{FCz}, \mathrm{Cz}, \mathrm{CPz}, \mathrm{Pz}$, and Oz. There were two inner lateral (IL) columns that included FP1/2, F3/4, FC3/4, C3/4, CP3/4, P3/4, and $\mathrm{O} 1 / 2$ and two outer lateral (OL) columns that included AF7/8, F7/8, FT7/8, T7/8, TP7/8, P7/8, and PO7/8. All sites were referenced to the left mastoid, and the impedance between each recording site and the reference was reduced to less than $5 \mathrm{k} \Omega$. An electrode was placed beneath the left eye (whose electrical activity was compared with an electrode placed above the left eye) to check for eye blinks and vertical eye movements. Another electrode was placed to the right of the subject's right eye (referenced to an electrode to the left of the left eye) to check for lateral eye movements. A final electrode was placed over the right mastoid (referenced to the left one) to monitor asymmetrical mastoid activity. (None was identified.) The electroencephalogram (EEG) was amplified by an SA Instrumentation system

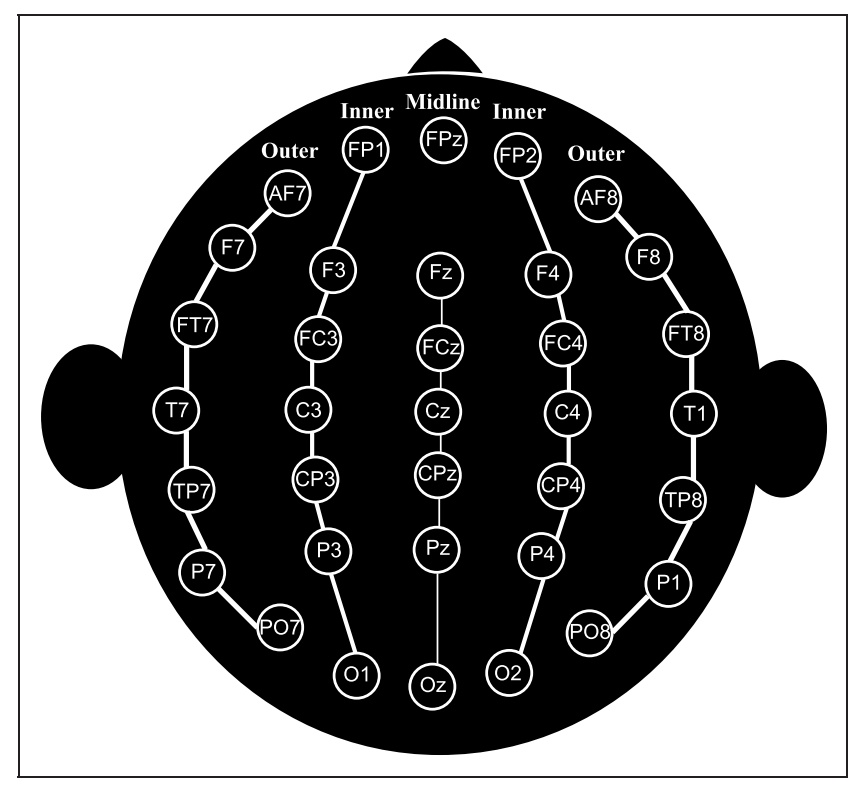

Figure 2. Montage illustrating the location of electrode sites, based on the International 10-20 system, which includes ML, two IL, and two OL columns. (model H\&W 32BA; San Diego, CA), using a band filter with negative 3-dB cutoffs of 0.01 and $40 \mathrm{~Hz}$ and continuously digitized $(200 \mathrm{~Hz})$.

\section{Data Analysis}

The viewing duration of each subject was measured in response to each stimulus type. Viewing duration was calculated as the temporal interval between stimulus onset and button press. RT and percent hit rate were measured for target events. RTs were calculated as the duration between target stimulus onset and foot pedal between 200 and $1800 \mathrm{msec}$. False alarm rates to novel and standard stimuli also were calculated.

A continuous record of the raw EEG was stored on hard disk. Off-line, EEG epochs for the three stimulus types (novels, targets, and standards) were averaged separately. Trials with eye movements or amplifier blocking were excluded from data analysis. For subjects who had greater than $15 \%$ eye blinks in response to any of the stimulus types, a blink correction program (using principal component analysis) was used (Dale, 1994) that computed the impact of the blink on the wave forms in each channel. The P3 component was defined as the peak positive amplitude between 350 and 850 msec after stimulus onset. P3 latency was defined as the time from stimulus onset to the wave peak at ML sites. $\mathrm{P} 3$ peak amplitudes were measured with respect to the average of the 100-msec prestimulus baseline.

In general, ERP data for each stimulus type were analyzed using analysis of variance (ANOVA), with cognitive status (high performing, average performing) as the between-subjects variables and electrode site as the within-subjects variable. P3 data were analyzed separately along the ML, IL column, and OL column electrode sites (Figure 2). Analyses of scalp distribution focused on determining whether there were anteroposterior differences across subject groups. In looking at interactions between scalp electrode site and other variables (e.g., cognitive status), the data were first normalized using a $z$ score technique (Kounios \& Holcomb, 1994) similar to the method recommended by McCarthy and Wood (1985) to avoid problems associated with interpreting Site $\times$ Factor interactions using ANOVA. The GeisserGreenhouse correction was applied to all repeated measures with greater than one degree of freedom. Regression/correlation analyses were used to determine the degree of association between pertinent variables (such as cognitive performance and P3 amplitude) across the entire group of old subjects.

\section{RESULTS}

\section{Participants}

Thirty-two individuals participated in this study. Data from one cognitively average performing old subject 
were not included in the analyses because her behavioral responses (viewing duration of novel stimuli) were more than three standard deviations from the mean of her group. Thus, we report on 16 cognitively high performing old and 15 cognitively average performing old subjects. The characteristics of each group are summarized in Table 1 that includes demographic information, the results on the more global cognitive measures (e.g., estimated IQ), composite percentile scores on the neuropsychological tests, and the pertinent statistical analyses.

The cognitively high performing group tended to be slightly older than the cognitively average performing group ( $p=.09$ ). Both groups had mean estimated IQ scores in the high average to superior range, with no significant differences in scores on the AMNART and Raven's Progressive Matrices Test. There were no group differences in years of education or score on the MMSE. Both groups were comparable in terms of sex, mood, and self-assessment of level of material comfort and wealth.

Cognitively high performing subjects had a higher mean composite percentile score for the six neuropsychological tests than cognitively average performing subjects (72.3 vs. 50.5 percentile, $p<.000001$ ) (Table 1 ). Cognitively high performing subjects also had a higher mean percentile score than cognitively average performing subjects on the two neuropsychological tests that focus on attention and executive functions, Digit Span/COWAT (79.2 vs. 43.1 percentile, $p<.0001$ ). Table 1 summarizes the results on specific neuropsychological tests.

\section{Behavioral Results}

\section{Viewing Duration}

Figure 3 is a bar graph illustrating the mean viewing durations in response to each stimulus type for the cognitively high and average subject groups. In response to novel stimuli, cognitively high performing subjects looked longer than cognitively average performing subjects, $F(1,29)=4.84, p<.05$. In response to target stimuli, cognitively average performing subjects looked longer than cognitively high performing subjects, $F(1,29)=$ $13.3, p<.01$. This difference between groups in viewing duration of targets remained even after RT for target detection was entered as a covariate, thus controlling for the fact that cognitively average performers had numerically longer RTs to targets (see next section). There were no group differences in viewing duration of standard stimuli. Across both groups, subjects looked at novel stimuli longer than standard stimuli, $F(1,29)=$ $7.55, p<.05$. The magnitude of this effect was larger for cognitively high than cognitively average performing subjects [Stimulus Type $\times$ Cognitive Status interaction, $F(1,29)=4.99, p<.05]$. Across both groups, subjects looked at target stimuli longer than standard stimuli, $F(1,29)=171.85, p<.0000001$. The difference was larger for cognitively average performing than cognitive-

Table 1. Subject Characteristics

\begin{tabular}{|c|c|c|c|c|c|}
\hline & \multicolumn{2}{|c|}{ Average } & \multicolumn{2}{|c|}{ High } & \multirow[b]{2}{*}{ p Value } \\
\hline & $M$ & $S D$ & $M$ & $S D$ & \\
\hline Age (years) & 70.1 & 4.3 & 73.0 & 4.9 & ns \\
\hline Years of education & 16.1 & 4.0 & 16.5 & 4.2 & $n s$ \\
\hline Sex (male/female) & \multicolumn{2}{|c|}{$7 / 8$} & \multicolumn{2}{|c|}{$7 / 9$} & $n s$ \\
\hline Raven-estimated IQ & 119.5 & 12.3 & 120.8 & 12.3 & $n s$ \\
\hline AMNART-estimated IQ & 116.9 & 9.6 & 121.3 & 8.8 & $n s$ \\
\hline MMSE & 28.5 & 1.6 & 29.2 & 0.8 & ns \\
\hline Digit Span & 15.9 & 3.5 & 19.6 & 4.3 & $<.05$ \\
\hline COWAT & 29.8 & 9.9 & 48.4 & 10.8 & $<.00005$ \\
\hline BNT & 54.9 & 3.3 & 56.9 & 3.3 & $<.05$ \\
\hline Category generated (animals) & 14.5 & 4.7 & 17.8 & 5.9 & $<.1$ \\
\hline WMS III Logical Memory II (Delayed Recall) & 25.0 & 7.5 & 28.8 & 3.9 & $<.1$ \\
\hline Benton Visual Retention Test (Correct) & 6.3 & 1.1 & 6.9 & 1.3 & $n s$ \\
\hline Composite Percentile Score & 50.5 & 9.2 & 72.3 & 9.8 & $<.000001$ \\
\hline COWAT/Digit Percentile Score & 43.1 & 20.5 & 79.2 & 17.7 & $<.0001$ \\
\hline
\end{tabular}


Figure 3. Viewing duration (mean \pm SEM; milliseconds) in response to each stimulus type.

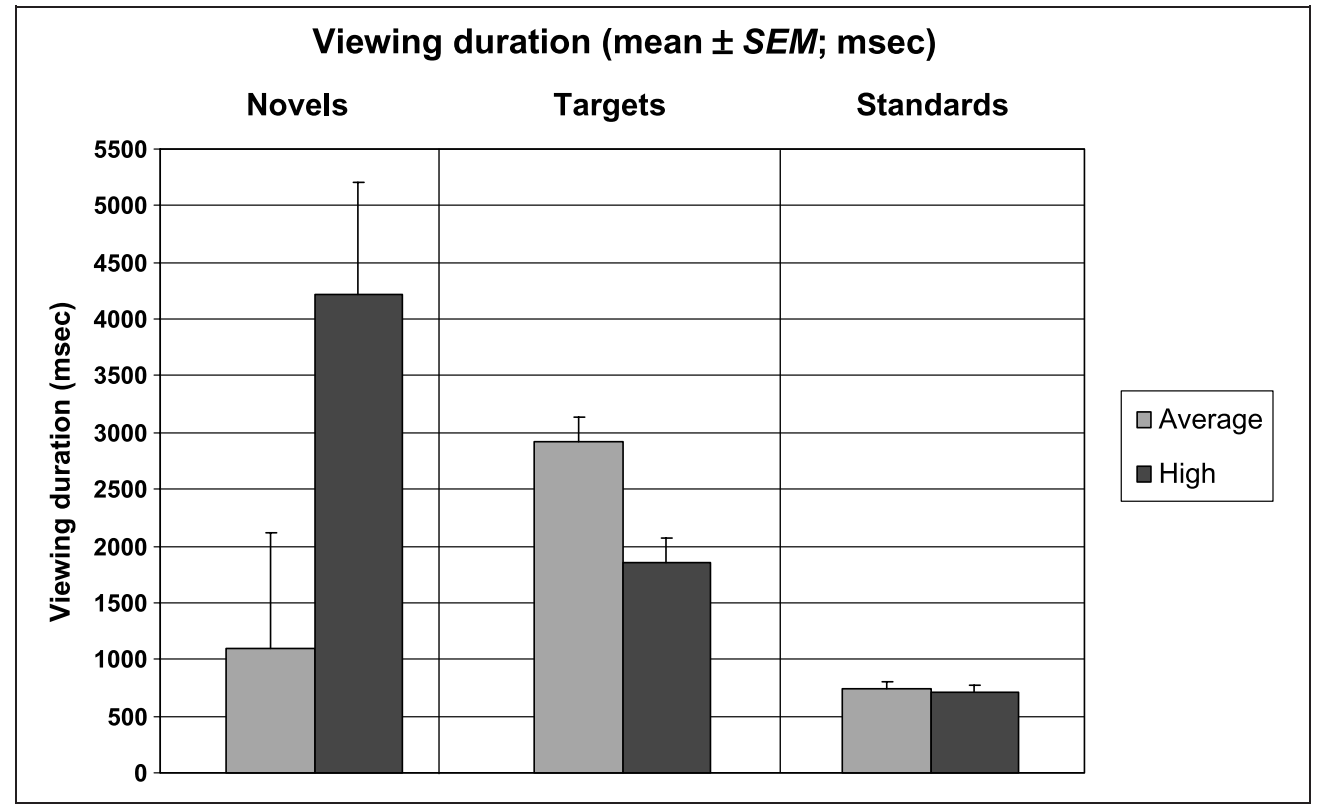

ly high performing subjects [Stimulus Type $\times$ Cognitive Status interaction, $F(1,29)=16.56, p<.001]$.

The comparison between viewing duration of novel and target stimuli was especially interesting. There was a significant interaction between stimulus type and group, $F(1,29)=9.32, p<.005$. Cognitively average performing individuals spent much more time viewing target than novel stimuli [targets: $2925 \pm 210$ msec; novels: $1099 \pm$ 1020 msec; $F(1,14)=33.61, p<.00005, \eta=0.84]$. In contrast, cognitively high performing individuals tended to spend more time looking at novel than target stimuli [targets: $1861 \pm 203$ msec; novels: $4224 \pm 987 \mathrm{msec}$; $F(1,15)=3.33, p=.09, \eta=0.43]$ (Figure 3).

\section{Hit Rates, False Alarms, and Target Reaction Time}

Cognitively high performers had a higher hit rate than cognitively average performers, $F(1,29)=5.87, p<.05$ (Table 2). No differences were found between groups in false alarm rates to novel or to standard stimuli. Cognitively high performing subjects had numerically shorter RTs to targets than cognitively average performing subjects $(888 \pm 55$ vs. $989 \pm 56 \mathrm{msec})$, although the differences were not reliable, $F(1,29)=1.65, p=.21$ (Table 2).

\section{P3 Latency}

Cognitively average performing subjects had a longer P3 latency to target hits than cognitively high performing subjects, $F(1,29)=8.77, p<.01$ (Table 2 ). This pattern was similar across all electrode sites (no Group $\times$ Site interaction). There were no significant differences between groups in P3 latency in response to novel or standard stimuli.

\section{P3 Amplitude}

Figure 4 illustrates the grand average ERPs at ML sites of each stimulus type for the cognitively high and average performing groups. Figure 5 illustrates surface potential maps for novels, target hits, and standards for both groups. Figure 6 presents bar graphs of the P3 amplitude in response to novels, target hits, and standards for both groups. In response to novel stimuli, cognitively high performing subjects generated a larger $\mathrm{P} 3$ response than cognitively average performing subjects at $\mathrm{ML}$ and $\mathrm{IL}$ sites [ML: $F(1,29)=5.87, p<.05$; IL: $F(1,29)=4.32$, $p<.05$; OL: $F(1,29)=1.62, p=.21$ ], with no difference in scalp distribution between groups. In response to target stimuli, there were no statistical differences

Table 2. Target Hit Rates, False Alarms, RTs, and P3 Latencies

\begin{tabular}{|c|c|c|c|c|c|}
\hline & \multicolumn{2}{|c|}{ Average } & \multicolumn{2}{|c|}{ High } & \multirow[b]{2}{*}{$p$ Value } \\
\hline & $M$ & SEM & $M$ & SEM & \\
\hline Correct hits (\%) & 87.9 & 2.4 & 97.0 & 1.2 & $<.05$ \\
\hline False alarm to novels (\%) & 0.5 & 0.3 & 0.3 & 0.2 & $n s$ \\
\hline False alarm to standards (\%) & 2.0 & 0.6 & 1.5 & 0.5 & $n s$ \\
\hline RT to targets (msec) & 989.0 & 56.0 & 888.1 & 55.0 & $n s$ \\
\hline \multicolumn{6}{|l|}{ Target P3 latency (msec) } \\
\hline Overall ML & 540.4 & 13.8 & 483.5 & 13.4 & $<.01$ \\
\hline $\mathrm{Fz}$ & 538.3 & 16.9 & 468.1 & 16.4 & $<.01$ \\
\hline $\mathrm{Cz}$ & 524.0 & 14.4 & 467.5 & 13.9 & $<.01$ \\
\hline $\mathrm{Pz}$ & 548.0 & 15.4 & 493.8 & 14.9 & $<.05$ \\
\hline
\end{tabular}


Figure 4. ML grand average ERP plots in response to novels, target hits, and standards. HE $=$ horizontal eye channel.

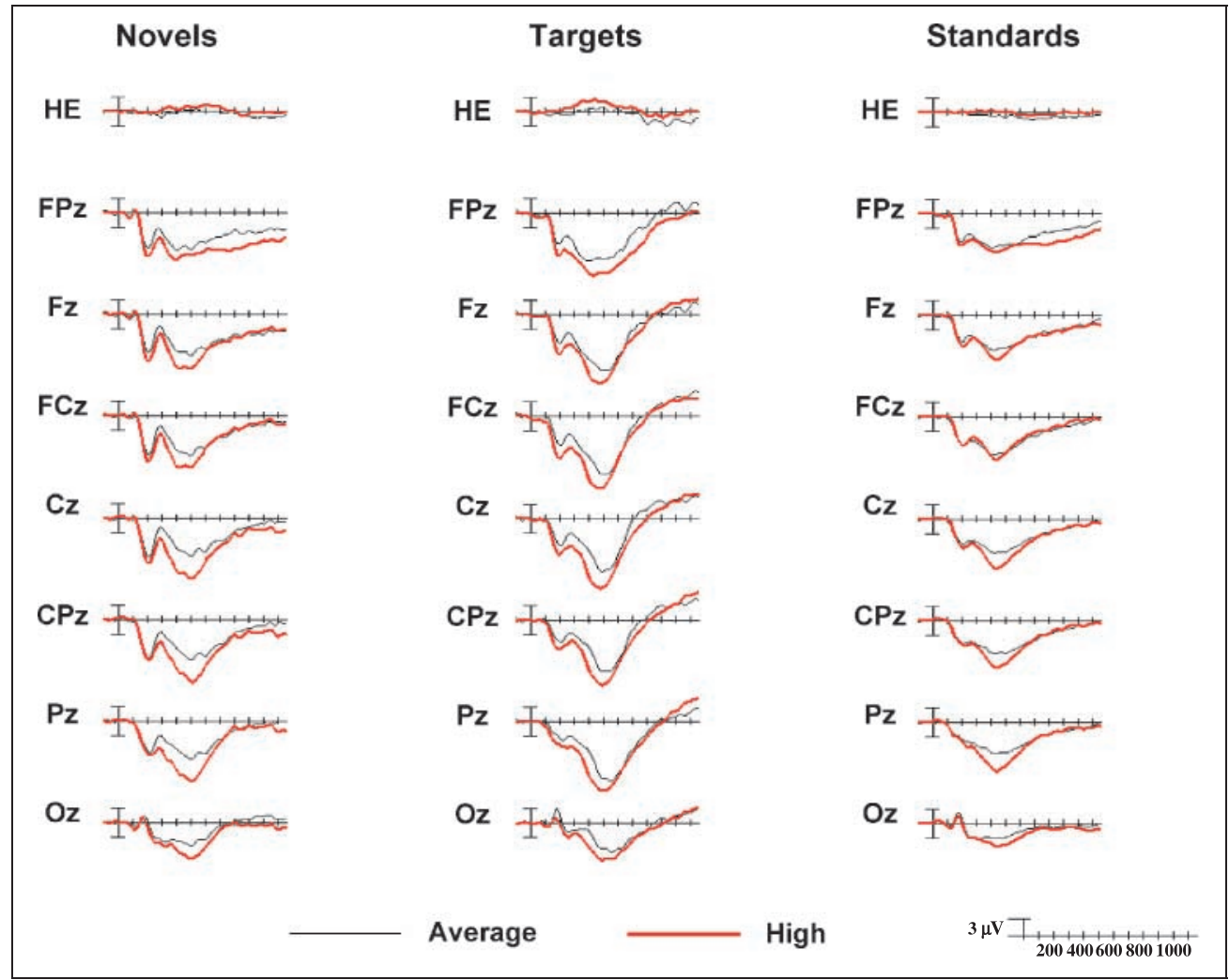

between groups in the P3 component, although cognitively high performers tended to have a larger response, especially at ML sites [ML: $F(1,29)=3.29, p=.08$; IL: $F(1,29)=2.62, p=.12 ;$ OL: $F(1,29)=1.23$, $p=.28]$. This pattern was similar across scalp locations (no Group $\times$ Site interaction). In response to standard stimuli, cognitively high performing subjects also generated a larger P3 response than cognitively average performing subjects at ML and IL sites [ML: $F(1,29)=$ $8.25, p<.01$; IL: $F(1,29)=9.29, p<.005$; OL: $F(1,29)=$ $2.16, p=.15]$. The largest differences between groups was observed at central and parietal locations, although
Figure 5. P3 surface potential maps for novels, target hits, and standards. Note that the range of the scales used differ across stimulus types.

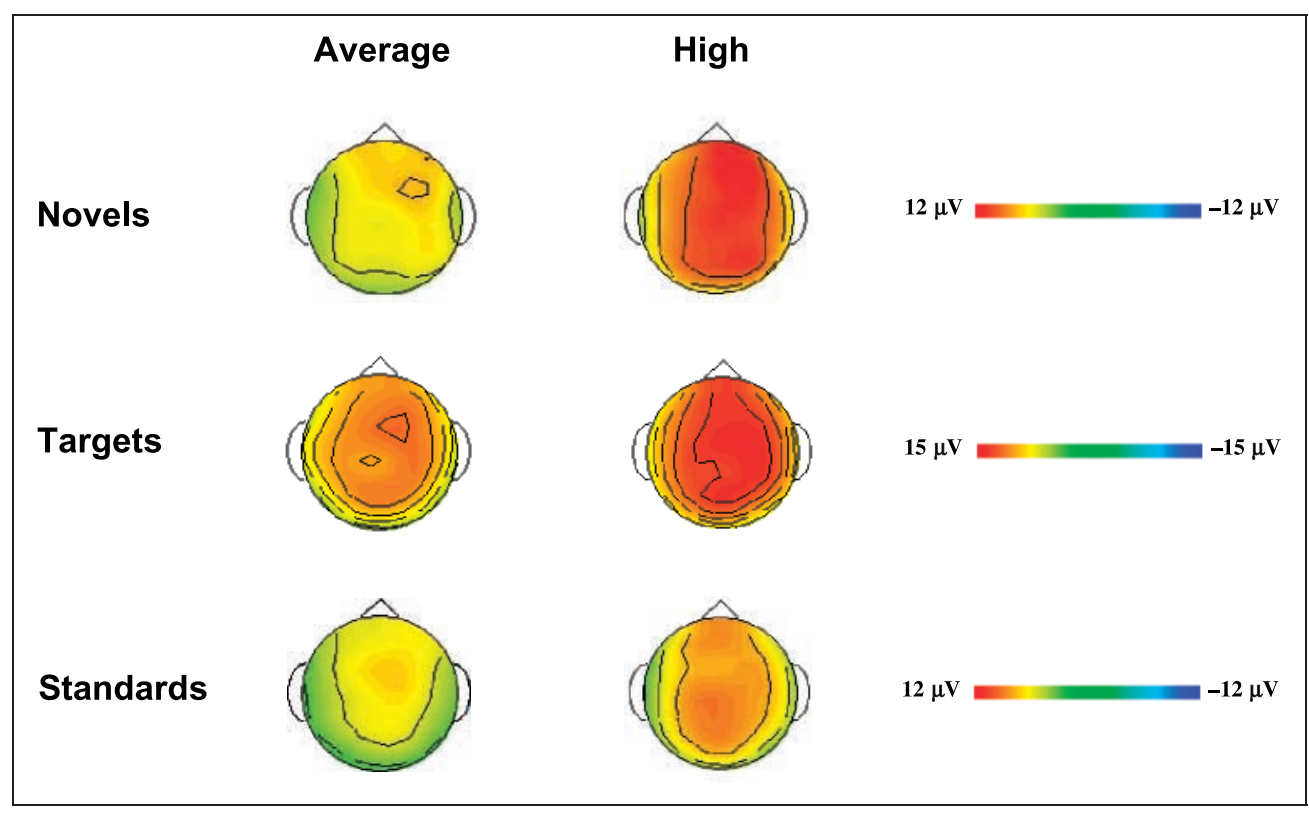


Figure 6. P3 amplitude in $\mu \mathrm{V}$ (mean $\pm S E M$ ) in response to novels, target hits, and standards at $\mathrm{Fz}, \mathrm{Cz}$, and $\mathrm{Pz}$.

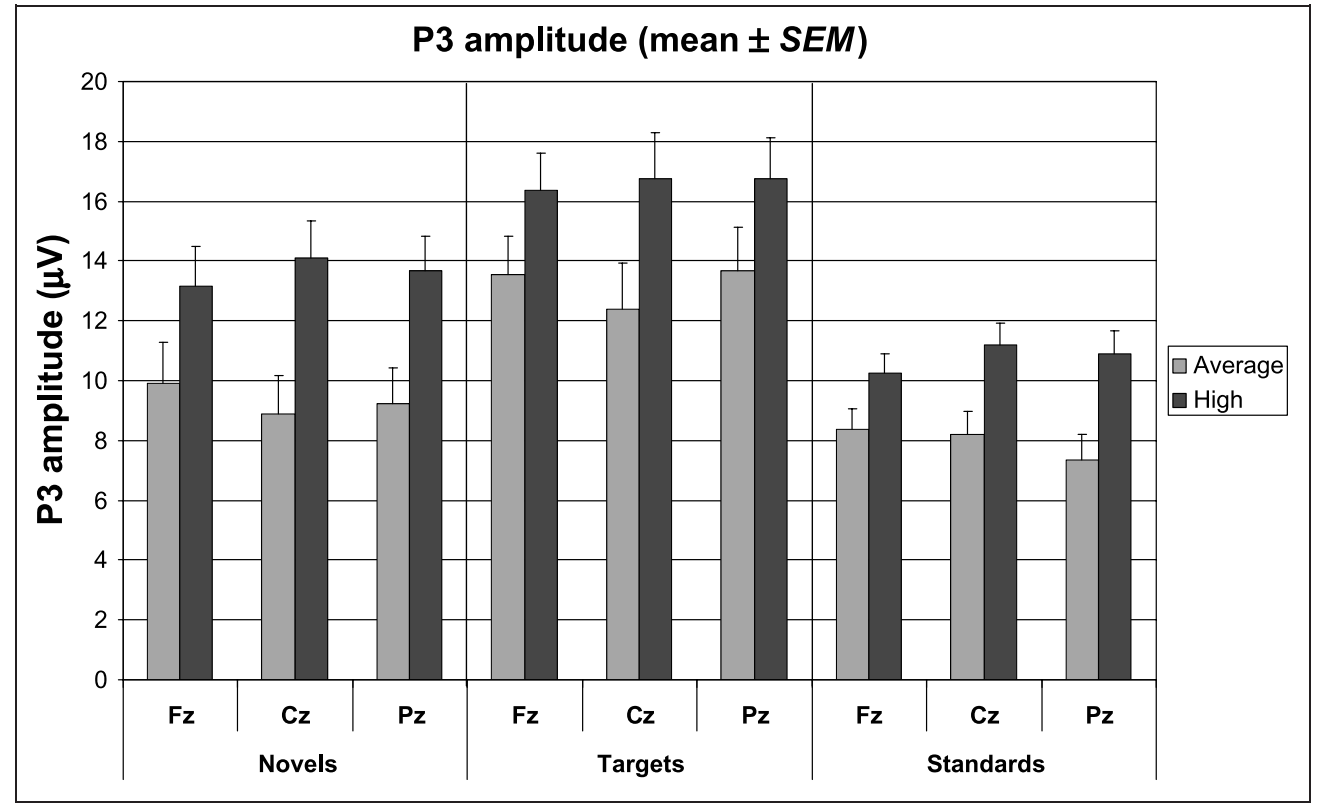

this pattern was only reliable at OL sites [Group $\times$ Site interaction; ML: $F(6,174)=1.74, p=.17$; IL: $F(6,174)=$ $2.11, p=.12$; OL: $F(6,174)=3.10, p<.05$ ]

Overall, the P3 to novel stimuli was larger than to standard stimuli [main effect of stimulus type; ML: $F(1,29)=$ 17.21, $p<.0005$; IL: $F(1,29)=23.95, p<.00005$; OL: $F(1,29)=39.71, p<.000001]$. The largest difference in $\mathrm{P} 3$ response to novel versus standard stimuli was seen at the most posterior sites [Stimulus Type $\times$ Site interaction; ML: $F(6,174)=6.14 .14, p<.001 ;$ IL: $F(6,174)=6.49, p<.001 ;$ OL: $F(6,174)=12.95$, $p<.000001$ ], with a similar pattern for both groups (no Stimulus Type $\times$ Site $\times$ Group interaction). Although in contrast to the viewing duration data, the interaction between group and stimulus type was not significant, the effect size in response to stimulus type for the two groups was in the same direction as the viewing duration data, being larger for the cognitively high performers than the cognitively average performers, especially at ML sites (ML: $\eta=0.69$ vs. 0.50 ; IL: 0.69 vs. 0.66; OL: 0.79 vs. 0.73).

The P3 to target stimuli was larger than to standard stimuli [main effect of stimulus type; ML: $F(1,29)=$ 55.52, $p<.0000001$; IL: $F(1,29)=74.08, p<.00000001$; OL: $F(1,29)=80.63, p<.00000001)$, with no interaction between group and stimulus type. The difference between the P3 response to target and standard stimuli was largest at fronto-central and parietal sites [Stimulus Type $\times$ Site interaction; ML: $F(6,174)=3.08, p<.05$; IL: $F(6,174)=2.50, p=.059 ;$ OL: $F(6,174)=6.65$, $p<.0005$ ] and was observed for both groups (no Stimulus Type $\times$ Site $\times$ Group interaction). Overall, the P3 to target stimuli was larger than to novel stimuli [ML: $F(1,29)=21.18, p<.0001$; IL: $F(1,29)=25.11$, $p<.00005$; OL: $F(1,29)=25.28, p<.00005]$. The smallest differences between $\mathrm{P} 3$ response to target and novel stimuli was observed at occipital sites [Stimulus Type $\times$ Site interaction; ML: $F(6,174)=3.84, p<.01$; IL: $F(6,174)=2.50, p=.06$; OL: $F(6,174)=2.65, p=.06]$, with a similar pattern for both groups (no Stimulus Type $\times$ Site $\times$ Group interaction). Although the interaction between group and stimulus type was not significant, the effect size in response to stimulus type for the two groups was smaller for cognitively high than the cognitively average performing subjects (ML: $\eta=$ 0.56 vs. 0.75 ; IL: 0.59 vs. 0.80 ; OL: 0.68 vs. 0.70 ).

\section{Regression and Correlation Analyses}

To further examine the relationship between pertinent variables (e.g., cognitive performance and viewing duration; cognitive performance and P3 amplitude), regression/correlation analyses were conducted. (Spearman's rho, $\rho$, was used when the data were not normally distributed.) Percentile composite score on neuropsychological tests correlated with the ratio of viewing duration of novels to viewing duration of targets ( $\rho=$ $.51, p<.01)$. Similarly, percentile score on tests of attention/executive functions (Digit Span/COWAT) correlated with the ratio of viewing duration of novels to viewing duration of targets $(\rho=.47, p<.01)$. The better the composite score or performance on tests of attention/executive function, the longer subjects looked at novel relative to target stimuli. Percentile score on tests of attention/executive functions correlated with overall P3 amplitude to novel stimuli at ML sites $(r=$ $.44, p<.05)$. The correlation was largest at $\mathrm{CPz}$ $(r=.48, p<.01)$ (Figure $7 \mathrm{~A})$. Percentile score on tests of attention/executive function and P3 latency to target stimuli were inversely correlated at ML sites $(r=-.47$, 


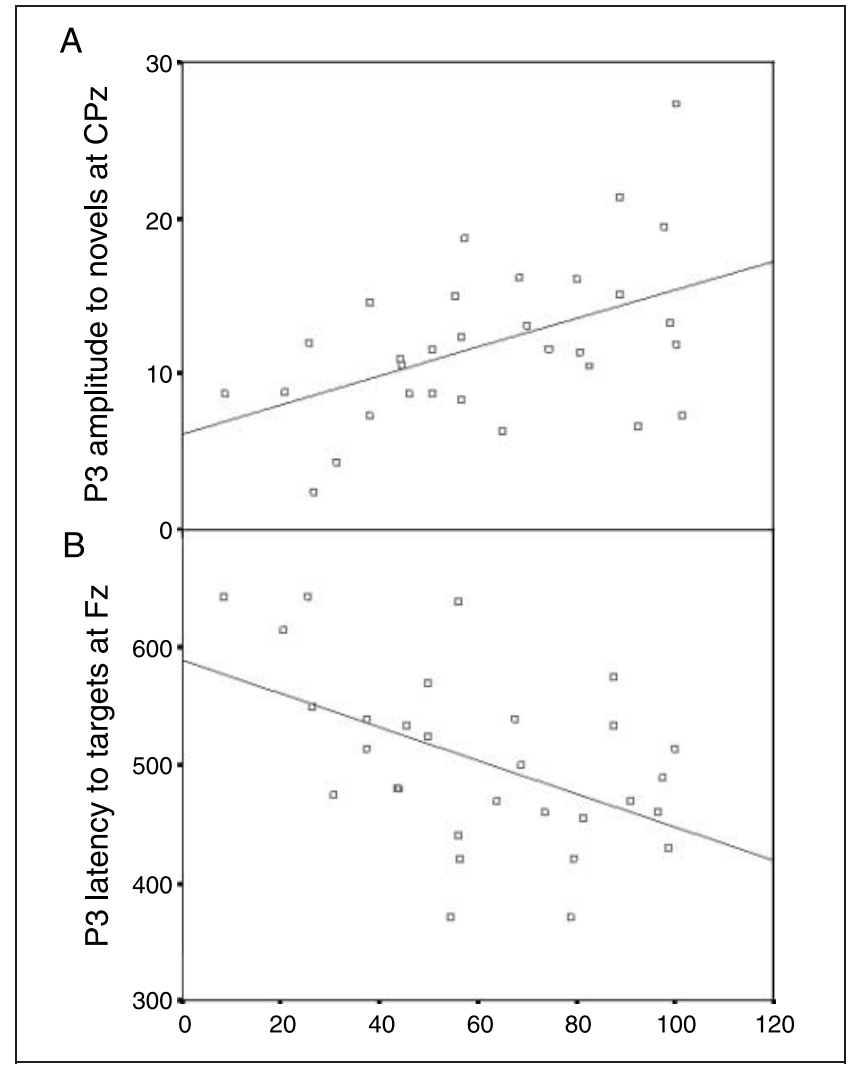

Figure 7. Plots of the relationship between percentile score on tests of attention/executive function and (A) P3 amplitude to novel stimuli at $\mathrm{CPz}$ and (B) P3 latency to target stimuli at Fz.

$p<.01)$, with the correlation being largest at Fz $(r=$ $-.51, p<.005$ ) (Figure 7B). The P3 amplitude to novel stimuli at Pz correlated with the ratio of viewing duration of novel to viewing duration of standard stimuli $(\rho=.40$, $p<.05)$ and with the ratio of viewing duration of novels to viewing duration of targets $(\rho=.45, p<.05)$.

\section{Novelty P3 Difference Wave}

Novelty P3 difference waves were also calculated using novel minus standard wave forms, which helped to isolate endogenous components more specifically related to novelty. Cognitively high performing old subjects had a numerically larger mean novelty P3 difference wave than cognitively average performing old subjects, although the difference between groups was not reliable $[5.76 \pm 0.76$ vs. $4.00 \pm 0.79 \mu \mathrm{V} ; F(1,29)=2.57, p=.12$, $\eta=0.28]$. Across the entire group of old subjects, the amplitude of the novelty $\mathrm{P} 3$ difference wave across ML sites correlated with percentile score on tests of attention/executive functions $(r=.41, p<.05)$; the larger the novelty P3 difference wave, the better the performance on tests of attention/executive function. The amplitude of the novelty $\mathrm{P} 3$ difference wave correlated with the ratio of viewing duration of novels to viewing duration of standards at $\mathrm{Cz}$ and $\mathrm{Pz}(\rho=.39, p<.05)$. In contrast to the P3 to novel stimuli and the novelty P3 difference wave, there was no correlation between the P3 amplitude to standard stimuli and the ratio of viewing duration of novels to standards.

\section{DISCUSSION}

The goal of this study was to compare the way in which cognitively high and cognitively average performing old adults process novel and target events. Members of both groups performed within the normal range on cognitive tests (with mean composite test scores above the 50th percentile) and exhibited no evidence of dementia. The two groups were well matched for pertinent variables, including sex, mood, and socioeconomic status. Of particular interest, there were no differences between groups in terms of years of education or estimated IQ, suggesting that their members had similar educational experiences and overall cognitive capacity earlier in their lives. One interpretation of the fact that the cognitively high functioning group currently performs significantly better on neuropsychological tests is that they have experienced more successful cognitive aging.

In an earlier study, we had observed no age-related differences in behavioral engagement by novel stimuli or in target P3 latency among cognitively high performing adults. We hypothesized that these results were a reflection of the cognitive competence of the high performing old subjects. However, caution needed to be exercised because inferences were based on null effects between groups. For example, the variant of the novelty oddball paradigm used may not have been sensitive enough to detect differences between groups. Also, in contrast to reports from the literature on aging and the $\mathrm{P} 3$ component, among our group of cognitively high performing adults, old subjects had a larger (not smaller) P3 amplitude. Based on theories about cognitive reserve and several recent functional imaging studies of high performing elders, we favored the view that the increase in size of the $\mathrm{P} 3$ component reflected a successful compensatory mechanism. In the current study, we tested four major hypotheses about differences between cognitively high and cognitively average performing old individuals in performance on a subjectcontrolled novelty oddball paradigm and found support for the first three.

Our first hypothesis was confirmed. Cognitively high performing elders spent more time viewing novel stimuli than did cognitively average performing elders. In contrast, cognitively average performing elders spent more time viewing target stimuli than did cognitively high performing elders. Across the entire group of old subjects, the better the performance on neuropsychological tests overall, and on tests of attention/executive functions in particular, the longer the viewing duration of 
novel relative to target stimuli. Cognitively high performing subjects also were more accurate in identifying targets than cognitively average performing subjects. This result was not because of the cognitively average performing subjects "trading" accuracy for speed, because they also had slower RTs to target stimuli.

Of particular interest, cognitively high performers had a shorter target P3 latency than cognitively average performers, which validated our second hypothesis. This result suggests that cognitively high performers were faster in the process of evaluating stimuli or updating working memory (Polich, 1996; Kutas et al., 1977). Prior research has indicated that aging (Polich, 1996), lower intellectual capacity (Jausovec \& Jausovec, 2000; O’Donnell, Friedman, Swearer, \& Drachman, 1992), and dementia (Olichney \& Hillert, 2004) are associated with increased target P3 latencies. None of these factors can account for the group differences that were observed in the current study. Cognitively high and average performers were matched for age and estimated IQ. Moreover, the study purposefully did not include cognitively low performers (i.e., those scoring in the bottom third on neuropsychological tests) to exclude old adults who may be exhibiting signs of mild cognitive impairment or early dementia. Consistent with our findings, prior studies have suggested that individuals with better concentration spans exhibit shorter target P3 latencies (Walhovd \& Fjell, 2002; Egan et al., 1994; O'Donnell et al., 1992; Polich, Howard, \& Starr, 1983). However, most of these investigations either did not include old subjects (Egan et al., 1994) or studied relatively few older than 60 years (O'Donnell et al., 1992; Polich et al., 1983) and made no direct comparisons within the subset of older adults.

Support was also found for our third hypothesis that cognitively high performing old subjects would generate a larger P3 response to novel stimuli than cognitively average performing old subjects. ${ }^{4}$ This result helps to elucidate earlier findings that across high performing adults, old subjects produced a larger P3 to novel and standard stimuli than their younger counterparts. If this age-related increase in P3 amplitude reflected a diminution of efficiency then one would expect cognitively average performing subjects to produce an even larger response. The opposite pattern was observed. Regression analysis confirmed that the better the attention/ executive functioning of the old subjects, the larger the P3 amplitude in response to novel stimuli. Moreover, the subjects who produced larger $\mathrm{P} 3$ responses to novel stimuli were more behaviorally engaged by novelty, as indexed by viewing duration. These data provide strong support for the notion that in older individuals, generation of a larger $\mathrm{P} 3$ amplitude represents a more adaptive response.

Our investigations add to the growing body of work that is examining the relationship between successful task performance among old subjects and age-related changes in neural activity. We have shown that cognitively high performing old subjects generate a larger P3 response to novel stimuli than both cognitively high performing younger subjects (Daffner et al., 2006) and cognitively average performing old subjects. As noted earlier, the increased size of the P3 component among cognitively high performing old adults is consistent with those results from the functional imaging literature demonstrating that old subjects who perform comparably to young subjects on source or episodic memory tasks appear to recruit wider areas of brain activity than young subjects or old subjects who perform worse (Cabeza et al., 2002; Rosen et al., 2002; Reuter-Lorenz et al., 2000). The current study suggests an analogous agerelated compensatory increase in neural activity may apply to the processing of novel and other visual stimuli in a subject-controlled novelty oddball task.

Our findings also lead to a modification of the framework that was proposed in the Introduction. The difference between cognitively high and average performing old subjects was not limited to the processing of novel events but also involved the more general treatment of visual stimuli. Our ERP data provide strong evidence for salient differences between cognitively high and cognitively average performing old adults in what has been termed overall cognitive set or neural state in response to the demands of a task (Rugg \& Morcom, 2005). Cognitively high performers generated a larger P3 amplitude to all stimulus types (with significant differences for novel and standard stimuli and a trend for target stimuli). These results suggest that cognitively high performing old adults manage the task by appropriating more resources than cognitively average performing old adults (and based on our earlier research, than cognitively high performing young and middle-aged adults). That this represents a successful "strategy" is indicated by their performing better behaviorally than cognitively average performing old subjects (and more like younger adults). One would predict that this strategy is most likely to break down as the demands of a task increase or in the face of dual task conditions in which there is competition for limited resources. If cognitively high performing old adults rely on more resources than their matched younger counterparts, the demands of the secondary task are likely to have a greater impact on the size of their P3 component (Wickens et al., 1983). We would also predict that under conditions that only require the appropriation of limited processing resources (e.g., more automatic tasks), there would be little or no difference in the size of the P3 to novel stimuli between cognitively high and cognitively average performing old subjects.

Although the difference between cognitively high and average performing old subjects in their overall cognitive set or neural state was one of the most striking outcomes of the study, there was also evidence for group differences that were more specific to novel stimuli. If 
the increase in $\mathrm{P} 3$ amplitude were only the reflection of an overall cognitive set/neural state, then we would not expect that the increased size of the P3 to novel stimuli would be associated with other relevant variables once we accounted for the increased size of the P3 to standard stimuli. Computation of the novelty P3 difference wave helped to isolate the ERP components that are more specifically related to novelty. The novelty $\mathrm{P} 3$ difference wave was numerically larger for the cognitively high performing group. Like the $\mathrm{P} 3$ to novel stimuli, the amplitude of the novelty $\mathrm{P} 3$ difference wave correlated with performance on tests of attention/executive function and with viewing duration of novel relative to standard stimuli. In contrast, the size of the P3 to standard stimuli did not correlate with viewing duration of novel relative to standard stimuli.

We did not find support for our final hypothesis that cognitively high performers would have a more anteriorly distributed P3 response to novel stimuli than cognitively average performers. There were no significant differences in P3 scalp distribution between the cognitively high and average performing groups. The null effect between groups makes it difficult to interpret the meaning of these results. On the one hand, because cognitively high performing old subjects did not exhibit a more anteriorly oriented $\mathrm{P} 3$, one cannot argue that the age-related anterior shift in scalp distribution represents a compensatory mechanism. On the other hand, because cognitively average performing old subjects did not exhibit a more anteriorly oriented $\mathrm{P} 3$, one cannot argue that the age-related shift in scalp distribution necessarily represents dysfunction of frontal executive systems (Fabiani, Friedman, \& Cheng, 1998; Friedman et al., 1993, 1998). Additional research is necessary to better understand this phenomenon.

Although the experiment was designed with cognitive performance as the independent variable, the causal relationship between cognitive performance and engagement by novelty remains to be elucidated. Increased responsiveness to novel events could be another marker of successful cognitive aging. However, there may be a complex interaction between sensitivity to novelty and cognitive competence. It is very plausible that individuals who are more engaged by novelty (as measured by viewing duration or the P3 amplitude) seek varied experiences and greater intellectual stimulation that can promote the genesis of neurons and synapses (Kempermann et al., 1997; Connor et al., 1981), which, in turn, can help to sustain cognitive abilities throughout adulthood (Scarmeas et al., 2003; Wilson et al., 2002; Rowe et al., 1998). Longitudinal studies of individuals at a similar level of cognitive competence, but who differ in terms of their level of engagement by novelty would be one strategy for addressing this question.

Our study focused on two groups of old adults who differed in their current level of cognitive performance. However, both groups had very similar levels of under- lying cognitive reserve, as indexed by equivalent years of education and estimated IQ (Stern, 2002). Although based on current theory, we would hypothesize that old adults with high cognitive reserve would generate a substantially larger $\mathrm{P} 3$ response to novel stimuli than old adults with low cognitive reserve, this remains to be determined. Of particular interest would be whether the groups differed in terms of the scalp distribution of the P3 component, as this may provide further clues about the functional significance of the age-related shift in scalp orientation.

We found substantial differences in the processing of novel and target events among elders who varied in terms of their cognitive competence. It will be very important to determine whether the same patterns are observed between cognitively high and average performing middle-aged and young adults. There are at least three possible outcomes that might be observed. First, both the pattern and magnitude of differences in behavioral and P3 response to novelty between cognitively high and average performers may be the same across age groups. Second, the magnitude of the difference between cognitively high and average performers may be larger for old adults. Third, there may be a more complex interaction between cognitive status and age. For example, among old subjects, those with greater cognitive competence may successfully compensate for age-related physiological changes by recruiting more neural resources, which would manifest as a larger P3 response to novel stimuli, whereas among younger subjects, those with greater cognitive competence may manage the task more efficiently, which would manifest as a smaller P3 response to novel stimuli. Ongoing research should provide greater insight into the relationship between responsiveness to novelty and cognitive competence across the lifespan.

\section{Acknowledgments}

We thank Hyemi Chong and Jenna Riis for their assistance with data analysis and manuscript preparation. This research was supported in part by NIA grant 1R01 AGO17935.

Reprint requests should be sent to Kirk R. Daffner, Division of Cognitive and Behavioral Neurology, Brigham and Women's Hospital, Harvard Medical School, 221 Longwood Avenue, Boston, MA 02115, or via e-mail: kdaffner@partners.org.

\section{Notes}

1. Results from the traditional novelty oddball paradigm have often led to the view that novel stimuli evoke a P3 that reflects an involuntary automatic process, whereas the target stimuli evoke a P3 that reflects voluntary attention (Knight \& Scabini, 1998; Knight, 1997). A detailed discussion of the relationship between the novelty $\mathrm{P} 3$ and $\mathrm{P} 3 \mathrm{a}$ or between the target $\mathrm{P} 3$ and $\mathrm{P} 3 \mathrm{~b}$ (or P300) is beyond the scope of the current article. Of note, recent evidence has challenged the notion of simple dichotomies between ERP response to novel and target stimuli or between the automatic and resource demanding processes 
of the P3a and P3b. Novel, nontarget deviant, and target events can elicit both an anteriorly oriented $\mathrm{P} 3 \mathrm{a}$ and a posteriorly oriented $\mathrm{P} 3 \mathrm{~b}$, although they tend to do so to varying degrees (Cycowicz \& Friedman, 2004; Dien, Spencer, \& Donchin, 2004; Gaeta, Friedman, \& Hunt, 2003). The novelty P3a can be modulated by the demands of the primary task (Yucel, Petty, McCarthy, \& Belger, 2005; Harmony et al., 2000) and in certain experimental contexts may serve as an index of the executive control system (Barcelo, Perianez, \& Knight, 2002). In the current study, these issues are not explicitly investigated.

2. To help control for individual differences among normal subjects in their tendency to spend time looking at visual stimuli (with some individuals moving through the stimulus set much more quickly than others) and among clinical populations in their underlying motor or cognitive speed, we constructed a measure of proportionality (viewing duration novels/viewing duration backgrounds) for each subject (Daffner, Mesulam, Scinto, et al., 2000; Daffner et al., 1998). This ratio is particularly informative because the novel stimuli are defined in terms of their deviance from standard stimuli.

3. However, using functional magnetic resonance imaging, Nielson et al. (2002) found that old subjects with worse inhibitory control exhibited larger cortical recruitment, and Madden, Whiting, Provenzale, and Huettel (2004) found that old subjects with faster RTs on a visual oddball task did not exhibit augmented frontal activity but increased thalamic and decreased putamen activity.

4. To the best of our knowledge, the finding of cognitively high performing old subjects having a larger P3 than cognitively average performing old subjects has not been reported in the literature. Studies have found differences in P3 amplitude between cognitively normal and demented elders, with the latter usually having smaller P3 amplitudes (Olichney \& Hillert, 2004). In young subjects, reports have varied regarding whether the target P3 amplitude increases (Jausovec \& Jausovec, 2000) or decreases (Egan et al., 1994) as a function of higher intellectual capacity. Walhovd and Fjell (2002) found a correlation between target P3 amplitude and performance on digit span, matrix reasoning, and block design, which did not remain significant after controlling for age. As noted earlier, our older subject groups had comparable estimated IQs and exhibited no evidence of dementia. Moreover, our cognitively high performing old subjects had a larger P3 than matched cognitively high performing middle-aged and young subjects, which is a very uncommon finding in the ERP literature (Daffner et al., 2006).

\section{REFERENCES}

American Psychiatric Association. (1994). Diagnostic and statistical manual of mental disorders (4th ed.). Washington, DC: American Psychiatric Association.

Anderer, P., Semlitsch, H., \& Saletu, B. (1996). Multichannel auditory event-related brain potentials: Effects of normal aging on the scalp distribution of N1, P2, N2 and P300 latencies and amplitudes. Electroencephalography and Clinical Neurophysiology, 99, 458-472.

Barcelo, F., Perianez, J. A., \& Knight, R. T. (2002). Think differently: A brain orienting response to task novelty. NeuroReport, 13, 1887-1892.

Beck, E. C., Swanson, C., \& Dustman, R. E. (1980). Long latency components of the visually evoked potential in man: Effects of aging. Experimental Aging Research, 6, 523-545.

Berlyne, D. (1960). Conflict, arousal and curiosity. New York: McGraw-Hill.

Cabeza, R., Anderson, N., Locantore, J., \& McIntosh, A. R. (2002). Aging gracefully: Compensatory brain activity in high-performing older adults. Neuroimage, 17, 1394-1402.

Connor, J. R., Melone, J. H., Yuen, A. R., \& Diamond, M. C. (1981). Dendritic length in aged rats' occipital cortex: An environmentally induced response. Experimental Neurology, 73, 827-830.

Cycowicz, Y. M., \& Friedman, D. (2004). The old switcheroo: When target environmental sounds elicit a novelty P3. Clinical Neurophysiology, 115, 1359-1367.

Daffner, K. R., Mesulam, M. M., Calvo, V., Faust, R., Scinto, L. F. M., \& Holcomb, P. J. (2000). An electrophysiological index of stimulus unfamiliarity. Psychophysiology, 37, 737-747.

Daffner, K. R., Mesulam, M. M., Scinto, L. F. M., Acar, D., Calvo, V., Faust, R., Chabrerie, A., Kennedy, B., \& Holcomb, P. (2000). The central role of the prefrontal cortex in directing attention to novel events. Brain, 123, 927-939.

Daffner, K. R., Mesulam, M. M., Scinto, L. F. M., Calvo, V., Faust, R., West, W. C., \& Holcomb, P. J. (2000). The influence of stimulus deviance on electrophysiologic and behavioral responses to novel events. Journal of Cognitive Neuroscience, 12, 393-406.

Daffner, K. R., Mesulam, M. M., Scinto, L. F. M., Cohen, L. G., Kennedy, B. P., West, W. C., \& Holcomb, P. J. (1998). Regulation of attention to novel stimuli by frontal lobes: An event-related potential study. NeuroReport, 9, 787-791.

Daffner, K. R., Rentz, D., Scinto, L. F. M., Faust, R., Budson, A. E., \& Holcomb, P. J. (2001). Pathophysiology underlying diminished attention to novel events in patients with early AD. Neurology, 56, 1377-1383.

Daffner, K. R., Ryan, K. K., Williams, D. M., Budson, A. E., Rentz, D., Wolk, D., \& Holcomb, P. J. (2006). Age-related differences in attention to novelty among cognitively high performing adults. Biological Psychology, 72, 67-77.

Daffner, K. R., Scinto, L. F. M., Weintraub, S., Guinessey, J., \& Mesulam, M. M. (1994). The impact of aging on curiosity as measured by exploratory eye movements. Archives of Neurology, 51, 368-376.

Daffner, K. R., Scinto, L. F. M., Weitzman, A. M., Faust, R., Rentz, D., \& Budson, A. E. (2003). Frontal and parietal components of a cerebral network mediating voluntary attention to novel events. Journal of Cognitive Neuroscience, 15, 294-313

Dale, A. M. (1994). Source localization and spatial discriminant analysis of event-related potentials: Linear approaches (brain cortical surface). Dissertation Abstracts International, 5507B, 2559.

Dien, J., Spencer, K. M., \& Donchin, E. (2004). Parsing the late positive complex: Mental chronometry and the ERP components that inhabit the neighborhood of the P300. Psychophysiology, 41, 665-678.

Egan, V., Chiswick, A., Santosh, C., Naidu, K., Remmington, J., \& Best, J. (1994). Size isn't everything: A study of brain volume, intelligence and auditory evoked potentials. Personality and Individual Differences, 17, 357-367.

Fabiani, M., \& Friedman, D. (1995). Changes in brain activity patterns in aging: The novelty oddball. Psychophysiology, 32, 579-594.

Fabiani, M., Friedman, D., \& Cheng, J. C. (1998). Individual differences in P3 scalp distribution in older adults, and their relationship to frontal lobe function. Psychophysiology, 35, 698-708.

Fjell, A. M., \& Walhovd, K. B. (2004). Life-span changes in P3a. Psychophysiology, 41, 575-583.

Folstein, M. F., Folstein, S. E., \& McHugh, P. R. (1975) "Mini-Mental State." A practical method for grading the cognitive state of patients for the clinician. Journal of Psychiatric Research, 12, 189-198. 
Friedman, D. (2003). Cognition and aging: A highly selective overview of event-related potential (ERP) data. Journal of Clinical and Experimental Neuropsychology, 25, 702-720.

Friedman, D., Kazmerski, V. A., \& Cycowicz, Y. M. (1998). Effects of aging on the novelty $\mathrm{P} 3$ during attend and ignore oddball tasks. Psychophysiology, 35, 508-520.

Friedman, D., Simpson, G., \& Hamberger, M. (1993). Age-related changes in scalp topography to novel and target stimuli. Psychophysiology, 30, 383-396.

Gaeta, H., Friedman, D., \& Hunt, G. (2003). Stimulus characteristics and task category dissociate the anterior and posterior aspects of the novelty P3. Psychophysiology, 40, 198-208.

Harmony, T., Bernal, J., Fernandez, T., Silva-Pereyra, J., Fernandez-Bouzas, A., Marosi, E., Rodriguez, M., \& Reyes, A. (2000). Primary task demands modulate P3a amplitude. Brain Research, Cognitive Brain Research, 9, 53-60.

Hunt, J. M. (1965). Intrinsic motivation and its role in psychological development. In D. Levine (Ed.), Nebraska Symposium on Motivation: Vol. XIII (pp. 189-282). Lincoln: University of Nebraska Press.

Ivnik, R. J., Malec, J. F., Smith, G. E., Tangalos, E. G., \& Petersen, R. C. (1996). Neuropsychological tests' norms above age 55: COWAT, BNT, MAE Token, WRAT-R Reading, AMNART, STROOP, TMT, and JLO. Clinical Neuropsychologist, 10, 262-278.

Jausovec, N., \& Jausovec, K. (2000). Correlations between ERP parameters and intelligence: A reconsideration. Biological Psychology, 55, 137-154.

Katzman, R. (1993). Education and the prevalence of dementia and Alzheimer's disease. Neurology, 43, 13-20.

Kempermann, G., Kuhn, H. G., \& Gage, F. H. (1997). More hippocampus neurons in adult mice living in an enriched environment. Nature, 386, 493-495.

Knight, R. T. (1997). Distributed cortical network for visual attention. Journal of Cognitive Neuroscience, 9, 75-91.

Knight, R. T., \& Scabini, D. (1998). Anatomic bases of event-related potentials and their relationship to novelty detection in humans. Journal of Clinical Neurophysiology, 15, 3-13.

Kosslyn, S. M., Alpert, N. M., Thompson, W. L., Chabris, C. F., Rauch, S. L., \& Anderson, A. K. (1994). Identifying objects seen from different viewpoints: A PET investigation. Brain, 117, 1055-1071.

Kounios, J. H., \& Holcomb, P. J. (1994). Concreteness effects in semantic processing: Event-related potential evidence supporting dual-coding theory. Journal of Experimental Psychology: Learning, Memory, and Cognition, 20, 804-823.

Kroll, J. F., \& Potter, M. C. (1984). Recognizing words, pictures, and concepts: A comparison of lexical, object and reality decisions. Journal of Verbal Learning and Verbal Behavior, 23, 39-66.

Kutas, M., McCarthy, G., \& Donchin, E. (1977). Augmenting mental chronometry: The P300 as a measure of stimulus evaluation time. Science, 197, 792-795.

Logan, J. M., Sanders, A. L., Snyder, A. Z., Morris, J. C., \& Buckner, R. L. (2002). Under-recruitment and nonselective recruitment: Dissociable neural mechanisms associated with aging. Neuron, 33, 827-840.

Madden, D. J., Langley, L. K., Denny, L. L., Turkington, T. G., Provenzale, J. M., Hawk, T. C., \& Coleman, R. E. (2002). Adult age differences in visual word identification: Functional neuroanatomy by positron emission tomography. Brain and Cognition, 49, 297-321.
Madden, D. J., Turkington, T. G., Provenzale, J. M., Denny, L. L., Hawk, T. C., Gottlob, L. R., \& Colleman, R. E. (1999). Adult age differences in the functional neuroanatomy of verbal recognition memory. Human Brain Mapping, 7 , $115-135$.

Madden, D. J., Whiting, W. L., Provenzale, J. M., \& Huettel, S. A. (2004). Age-related changes in neural activity during visual target detection measured by fMRI. Cerebral Cortex, 14, 143-155.

McCarthy, G., \& Wood, C. C. (1985). Scalp distributions of event-related potentials: Ambiguity associated with analysis of variance models. Electroencephalography and Clinical Neurophysiology, 62, 203-208.

Nielson, K. A., Langenecker, S. A., \& Garavan, H. (2002). Differences in the functional neuroanatomy of inhibitory control across the adult life span. Psychology and Aging, $17,56-71$.

O'Donnell, B. F., Friedman, S., Swearer, J. M., \& Drachman, D. A. (1992). Active and passive P3 latency and psychometric performance: Influence of age and individual differences. International Journal of Psychophysiology, 12, 187-195.

Olichney, J. M., \& Hillert, D. G. (2004). Clinical applications of cognitive event-related potentials in Alzheimer's disease. Physical Medicine and Rehabilitation Clinics of North America, 15, 205-233.

Piaget, J. (1952). The origins of intelligence in children (M. Cook, Trans.). New York: International University Press.

Polich, J. (1996). Meta-analysis of P300 normative aging studies. Psychophysiology, 33, 334-353.

Polich, J., Howard, L., \& Starr, A. (1983). P300 latency correlates with digit span. Psychophysiology, 20, 665-669.

Raven, J. C., Court, J. H., \& Raven, J. (1995). Coloured progressive matrices, section 2. In Manual for Raven's Progressive Matrices and Vocabulary Scales (pp. 1-73). Oxford: Oxford Psychologists Press.

Reuter-Lorenz, P. A., Jonides, J., Smith, E. E., Hartley, A., Miller, A., Marshuetz, C., \& Koeppe, R. A. (2000). Age differences in the frontal lateralization of verbal and spatial working memory revealed by PET. Journal of Cognitive Neuroscience, 12, 174-187.

Rosen, A. C., Prull, M. W., O'Hara, R., Race, E. A., Desmond, J. E., Glover, G. H., Yesavage, J. A., \& Gabrieli, J. D. (2002). Variable effects of aging on frontal lobe contributions to memory. NeuroReport, 13, 2425-2428.

Rowe, W. B., Spreekmeester, E., Meaney, M. J., Quirion, R., \& Rochford, J. (1998). Reactivity to novelty in cognitivelyimpaired and cognitively-unimpaired aged rats and young rats. Neuroscience, 83, 669-680.

Rugg, M. D., \& Morcom, A. M. (2005). The relationship between brain activity, cognitive performance, and aging. In R. Cabeza, L. Nyberg, \& D. Park (Eds.), Cognitive neuroscience of aging: Linking cognitive and cerebral aging (pp. 132-154). New York: Oxford University Press.

Ryan, J., \& Paolo, A. (1992). A screening procedure for estimating premorbid intelligence in the elderly. Clinical Neuropsychologist, 6, 53-62.

Rypma, B., \& D'Esposito, M. (2000). Isolating the neural mechanisms of age-related changes in human working memory. Nature Neuroscience, 3, 509-515.

Satz, P. (1993). Brain reserve capacity on symptom onset after brain injury: A formulation and review of evidence for threshold theory. Neuropsychology, 7, 273-295.

Scarmeas, N., Zarahn, E., Anderson, K. E., Habeck, C. G., Hilton, J., Flynn, J., Marder, K. A., Bell, K. L., Sackheim, H. A., Van Heertum, R. L., Moeller, J. R., \& Stern, Y. (2003). Association of life activities with cerebral blood flow in Alzheimer disease: Implications for the cognitive reserve hypothesis. Archives of Neurology, 60, 359-365. 
Spreen, O., \& Strauss, E. (1998). A compendium of neuropsychological tests: Administration, norms, and commentary (2nd ed.). New York: Oxford University Press.

Stern, Y. (2002). What is cognitive reserve? Theory and research application of the reserve concept. Journal of the International Neuropsychological Society, 8, 448-460.

Swan, G. E., \& Carmelli, D. (1996). Curiosity and mortality in aging adults: A 5-year follow-up of the Western Collaborative Group Study. Psychology and Aging, 11, 449-453.

Tombaugh, T. N., \& Hubley, A. M. (1997). The 60-item Boston Naming test: Norms for cognitively intact adults aged 25 to 88 years. Journal of Clinical and Experimental Neuropsychology, 19, 922-932.

Verleger, R., Neukäter, W., Kömpf, D., \& Vieregge, P. (1991). On the reasons for the delay of P3 latency in healthy elderly subjects. Electroencephalography and Clinical Neurophysiology, 79, 488-502.

Walhovd, K., \& Fjell, A. (2001). Two- and three-stimuli auditory oddball ERP tasks and neuropsychological measures in aging. NeuroReport, 12, 3149-3153.

Walhovd, K. B., \& Fjell, A. M. (2002). The relationship between P3 and neuropsychological function in an adult life span sample. Biological Psychology, 62, 65-87.

Wechsler, D. (1997a). Wechsler Adult Intelligence Scale.
WAIS-III. Administration and scoring manual (3rd ed.). San Antonio, TX: The Psychological Corporation.

Wechsler, D. (1997b). Wechsler Memory Scale. WMS-III Administration and scoring manual (3rd ed.). San Antonio, TX: The Psychological Corporation.

Wickens, C., Kramer, A., Vanasse, L., \& Donchin, E. (1983). Performance of concurrent tasks: A psychophysiological analysis of the reciprocity of information-processing resources. Science, 221, 1080-1082.

Wilson, R. S., Mendes de Leon, C. F., Barnes, L. L., Schneider, J. A., Bienias, J. L., Evans, D. A., \& Bennett, D. A. (2002). Participation in cognitively stimulating activities and risk of incident Alzheimer disease. Journal of American Medical Association, 287, 742-748.

Yesavage, J. A., Rose, T. L., \& Lapp, D. (1981). Validity of the Geriatric Depression Scale in subjects with senile dementia. Palo Alto, CA: Veterans Administration Medical Clinic.

Youngjohn, J. R., Larrabee, G. J., \& Crook, T. H. (1993). New adult- and education-correction norms for the Benton Visual Retention Test. Clinical Neuropsychologist, 7, 155-160.

Yucel, G., Petty, C., McCarthy, G., \& Belger, A. (2005). Visual task complexity modulates the brain's response to unattended auditory novelty. NeuroReport, 16, 1031-1036. 
Copyright of Journal of Cognitive Neuroscience is the property of MIT Press and its content may not be copied or emailed to multiple sites or posted to a listserv without the copyright holder's express written permission. However, users may print, download, or email articles for individual use. 